\title{
Épocas de semeadura de milho na região norte de Mato Grosso
}

\author{
Cassiano Spaziani PEREIRA ${ }^{1,2^{*}}$, Ezequiel GEISE² ${ }^{2}$ Ivan Vilela Andrade FIORINI ${ }^{1}$, Anderson LANGE $^{1,2}$ \\ ${ }^{1}$ Programa de Pós-Graduação em Agronomia, Universidade Federal de Mato Grosso, Sinop, MT, Brasil. \\ ${ }^{2}$ Instituto de Ciências Agrárias e Ambientais, Universidade Federal de Mato Grosso, Sinop, MT, Brasil. \\ *E-mail: caspaziani@yahoo.com.br
}

Recebido em agosto/2017; Aceito em dezembro/2017.

\begin{abstract}
RESUMO: Existem poucas informações sobre a melhor época de semeadura de milho, durante o período da "segunda safra" no norte de Mato Grosso. O objetivo do trabalho foi verificar o comportamento produtivo de três híbridos de milho, semeados em seis épocas, durante a "segunda safra," ou "safrinha", no norte de Mato Grosso, Sinop-MT. O experimento foi conduzido em um Latossolo Vermelho Amarelo distrófico típico argiloso, entre janeiro e julho de 2014. O delineamento experimental foi em blocos ao acaso, com quatro repetições em esquema fatorial 3 x 6. Utilizou-se três híbridos comerciais simples e "precoces": Maximus ${ }^{\circledR}$; Truck (Syn7316)® e Status (Syn7205)®. As épocas de semeadura ocorreram aos 0, 7, 14, 21, 28 e 35 Dias após a semeadura de 26/01, correspondendo as datas de 26/01;02/02;09/02; 16/02; 23/02 e 02/03 de 2014, respectivamente. Avaliou-se a altura de plantas, área foliar, massa seca, teor relativo de água e produtividade da cultura. No florescimento, os menores teores de água nas folhas ocorreram nas plantas semeadas entre os dias $16 / 02$ e 23/02. O crescimento vegetativo do milho foi o menor na época de semeadura entre os dias 09/02 a 23/02. Os híbridos Truck ${ }^{\circledR}$, Máximus ${ }^{\circledR}$ e Status ${ }^{\circledR}$ não apresentaram diferença de produtividade e são mais produtivos quando semeados no final do período de segunda safra, entre os dias 16/02 a 02/03.
\end{abstract}

Palavras-chave: Zea mays L, milho segunda safra, matéria seca, área foliar, teor relativo de água.

\section{Maize seed times in the North region of Mato Grosso}

\begin{abstract}
Were not sufficient information's about the best time sowing of corn crop, during period of maize off-season in the north of Mato Grosso. The objective of this work was to verify the productive behavior of three maize hybrids, sown in six seasons, during the "second harvest," in the north of Mato Grosso, SinopMT. The experiment was conducted in a typical clayey dystrophic Yellow Red Latosol between January and July 2014. The experimental design was a randomized complete block design with four replicates in a $3 \times 6$ factorial scheme. Three commercial hybrids were used: Maximus ${ }^{\circledR}$; Truck (Syn7316) ${ }^{\circledR}$ and Status (Syn7205) ( . Sowing times occurred on day after sowing of date based of $01 / 26$; respectively for datas: $01 / 26$; $02 / 02$; $09 / 02 ; 16 / 02 ; 23 / 02$ and $02 / 03$ of 2014 . The variables analyzed the height of plants, stem diameter, leaf area, dry matter, relative water content and crop productivity were evaluated. At flowering, the lowest leaf water contents occurred in the plants sown between February 16 and February 23. The maize vegetative growth was the lowest in the sowing season between 09/02 to 23/02. The Hybrids Truck, Maxima and Status had a productivity difference and are more productive when sown at the end of the second crop period, between February 16 to March 2.
\end{abstract}

Keywords: Zea mays L., maize off-season, dry matter, leaf area, relative water content.

\section{INTRODUÇÃO}

O Milho (Zea mays) é um dos cereais mais produzidos e consumidos no mundo, devido ao grande potencial nutricional e preço acessível desta comodity, seu grão é utilizado em rações, na alimentação humana "in natura" e processado. O Mato Grosso destaca-se como grande produtor de milho, atingindo na safra 2016/2017, produção de 25,55 milhões de toneladas de grãos sendo que a "segunda safra" ou "safrinha" representou $98 \%$ de toda a produção de milho do Estado (CONAB, 2017).

Além do aumento na participação da produção nacional de milho, a "segunda safra" tem aumentado seus níveis de produtividade em todas as regiões produtoras de milho no Brasil, principalmente devido ao aperfeiçoamento das técnicas de cultivo e ao elevado potencial produtivo dos híbridos utilizados (CRUZ et al., 2010).
O milho "segunda safra" possui esta designação, pois, dentro do ciclo da safra, sua semeadura é realizada após a colheita da cultura de verão, no caso de Mato Grosso a soja, dessa forma, a época de semeadura ocorre entre os meses de janeiro a março, dependendo o seu planejamento da época de implantação e do ciclo da cultura de verão (FORSTHOFER, 2006). Com isso as pesquisas têm se intensificado na redução dos ciclos das culturas de verão e do próprio milho (BORTOLINI, 2007).

Apesar de haver várias tecnologias para o milho segunda safra, algumas informações básicas aos produtores ainda não estão disponíveis, dentre elas a melhor época de semeadura, principalmente em Mato Grosso onde estas informações são muito escassas.

O conhecimento da melhor época de semeadura do milho é consequência da interação sinérgica entre genótipo e o ambiente, sendo a melhor época de semeadura aquela que 
coincide com maior crescimento vegetativo, sem limitações hídricas, atingindo maiores produtividades (GONÇALVES et al., 2002).

Em estudos de época de semeadura deve-se levar em consideração, além da disponibilidade hídrica, a temperatura e a radiação solar, fatores estes que interferem na fenologia da planta e afetam o seu desenvolvimento (SANGOI et al., 2007).

Diante do exposto, deve-se cada vez mais buscar informações de épocas de semeadura nas diversas regiões brasileiras, para que os riscos de perda fiquem o mais próximo de zero, e com isso possa-se interferir no sistema como um todo, gerando informações, para a safra de "verão" e da "segunda safra", visando liberar a área no tempo certo para cada cultivo (SANS et al., 2012).

Apesar de ser um estudo extremamente básico, não existem informações confiáveis e científicas sobre as épocas limite de semeadura de milho, após o cultivo da soja no norte de Mato Grosso. Desta forma o objetivo do trabalho foi verificar o comportamento de três híbridos comerciais de milho (Status ${ }^{\circledR}$, Maximus ${ }^{\circledR}$ e Truck ${ }^{\circledR}$ ) em seis épocas de semeadura da segunda safra (janeiro a março) na região de Sinop - MT.

\section{MATERIAL E MÉTODOS}

O experimento foi conduzido de janeiro a julho de 2014, na área experimental da Universidade Federal de Mato grosso (UFMT), Campus de Sinop - MT, de coordenadas $11^{\circ} 86^{\prime}$ 46 " S e $55^{\circ} 48^{\prime} 38^{\prime \prime} \mathrm{O}$ e $345 \mathrm{~m}$ de altitude. O clima da região, segundo classificação de Koppen, é do tipo Am, com precipitação pluvial média anual de $2200 \mathrm{~mm}^{-a n o^{-1}}$, temperatura média anual de $25{ }^{\circ} \mathrm{C}$ e umidade relativa do ar média anual de 66\% (SOUZA et al., 2013).

$\mathrm{O}$ delineamento experimental foi em blocos ao acaso, com quatro repetições, em esquema fatorial $3 \times 6$, totalizando 18 tratamentos e 72 parcelas. As parcelas foram constituídas por cinco linhas de semeadura de cinco metros de comprimento, totalizando $12,5 \mathrm{~m}^{2}$. O primeiro fator foram os três híbridos: maximus ${ }^{\circledR}$; Truck ${ }^{\circledR}(\operatorname{Syn} 7316)$ e Status ${ }^{\circledR}$ (Syn7205) e o segundo fator foram as seis épocas de semeadura (semanalmente) aos 0, 7, 14, 21, 28 e 35 Dias após a semeadura de 26/01, correspondendo as datas de 26/01; 02/02; 09/02; 16/02; 23/02 e 02/03 de 2015, respectivamente.

Antes de realizar o preparo do solo e semeadura, realizouse amostragem de solo na profundidade de 0-0,20 m, coletando-se cinco amostras simples, que constituíram uma amostra composta. Após a coleta a amostra foi enviada ao Laboratório de Análise de Solos da UFMT/Sinop credenciado para realização de análises químicas.

A análise química do solo teve os seguintes valores:

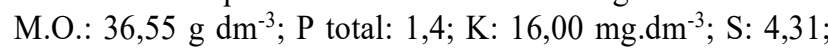
Ca: 2,71; Mg: 1,76; Al: 0,00; H+Al: 2,90; CTC a pH 7,0: 7,21 mmolc.dm ${ }^{-3} . \mathrm{V}=59,78 \% ; \mathrm{Ca} / \mathrm{Mg}: 1,74 ; \mathrm{Ca} / \mathrm{K}: 67,75$; $\mathrm{Mg} / \mathrm{K}: 39,00$. Os teores de micronutrientes foram em mg.dm 3, B: 0,19; Cu: 0,17; Fe: 81,69; Mn: 9,77 e Zn 0,64. A análise físico-química, $\mathrm{pH}\left(\mathrm{H}_{2} \mathrm{O}\right)$ : 6,0. A análise física do solo teve a proporção: 308; 141 e 551 g. $\mathrm{kg}^{-1}$ de areia, silte e argila respectivamente.

O solo da área do experimento foi Classificado como Latossolo Vermelho Amarelo distrófico (EMBRAPA, 2006), com preparo convencional, sendo o ano do experimento o segundo ano de semeadura. No primeiro ano, safra
2012/2013, a área foi semeada com arroz no verão e feijão na safrinha. Na safra de verão 2013 a área ficou vazia sendo apenas dessecada com o herbicida Glifosate anteriormente ao experimento.

O solo foi corrigido com calcário ainda durante o verão para que a saturação de bases atingisse $60 \%$. A adubação fundamentou-se na análise de solo, utilizando-se de 500 $\mathrm{kg} / \mathrm{ha}$ do formulado 04-20-20, correspondendo à recomendação por hectare de $50 \mathrm{Kg}$ de $\mathrm{N}, 100 \mathrm{~kg}$ de $\mathrm{P}_{2} \mathrm{O}_{5}$ e $100 \mathrm{~kg}$ de $\mathrm{K}_{2} \mathrm{O}$ na semeadura. Aos 15 Dias após a Emergência (DAE) realizou-se adubação de cobertura a lanço com aplicação de $\mathrm{N}$ na forma de ureia na dose de $200 \mathrm{~kg} \mathrm{ha}^{-1}$ e de enxofre elementar (90\% de enxofre) na dose de $45 \mathrm{Kg}$ de $\mathrm{S}$ ha $^{-1}$. Como os híbridos eram da tecnolgia Bt e RR, o controle de plantas daninhas foi realizado com uso de Herbicidas com o Principio ativo Glifosato, na dose de 1920 gramas de e.a.ha ${ }^{-1}$. O tratamento de sementes (TS) foi a base de imidacloprid e Fipronil, não havendo a necessidade de controle de lagarta após a aplicação em TS. Realizou-se o controle de percevejo da soja com a aplicação de inseticida, a base de acefato, no início da emergência V2.

Após o preparo, dessecação e adubação da área, realizouse a semeadura manual dos híbridos nas diferentes épocas, adotando-se o espaçamento entre linhas de $0,5 \mathrm{~m}$ e o semeio de três plantas. $\mathrm{m}^{-1}$, obtendo-se a população de 60 mil plantas. ha ${ }^{-1}$ para todos os híbridos.

Coletou-se os dados meteorológicos junto a Estação Meteorológica da UFMT, distante $200 \mathrm{~m}$ do experimento. (Figuras 1a; 1b e 1c).

O crescimento vegetativo das plantas foi avaliado no estádio reprodutivo R1 determinando-se: a altura das plantas e a massa seca da parte aérea. A altura das plantas foi obtida com o auxílio de uma régua graduada, obtendo-se os valores a partir do solo até a folha bandeira do milho.

Coletou-se a parte aérea de duas plantas por parcela e as plantas foram levadas ao laboratório de Sementes da UFMT. No laboratório as folhas foram destacadas, condicionadas em sacolas de papel e colocadas em estufa de circulação forçada a $60^{\circ} \mathrm{C}$ até atingirem o peso constante, obtendo-se a massa seca da parte aérea (PEREIRA et al., 2014).

Ainda no estádio R1 determinou-se o teor relativo de água das folhas, conforme metodologia utilizada em milho por (MAIA et al., 2007). Para esta variável, foram coletadas, antes do nascer do sol, manualmente três folhas totalmente expandidas do terço médio das plantas. Após a coleta, as folhas foram colocadas em sacolinhas plásticas e acondicionadas em um isopor com gelo, para evitar perda de água pelas folhas, que foram imediatamente transportadas até o laboratório para as análises.

No laboratório, com o auxílio de um anel circular de metal, com $1,3 \mathrm{~cm}$ de diâmetro, retirou-se três discos de tecidos foliares, evitando-se a presença de nervuras ou qualquer tipo de dano nas folhas. Após a obtenção destes discos os mesmos foram pesados em balança de precisão $(0,0005 \mathrm{~g})$ obtendo-se a massa fresca $\left(m_{f}\right)$. Logo após os mesmos discos foram colocados em um béquer com água destilada por 12 horas até atingir a turgescência, quando foram pesados e obtendo-se a massa túrgida $\left(m_{t}\right)$. Por fim os mesmos discos foram acondicionados em sacos de papel e colocados em estufa de circulação forçada a $60^{\circ} \mathrm{C}$ até atingirem o peso constante, obtendo-se a massa seca $\left(m_{s}\right)$. Com a obtenção da $m_{f}, m_{t}$ e $m_{s}$ pode-se obter o Teor Relativo de Água (TRA) nas folhas de milho (\%) (Equação 1). 
$\operatorname{TRA}(\%)=[(\mathrm{mf}-\mathrm{ms}) /(\mathrm{mt}-\mathrm{ms})] * 100 \quad$ (Equação 1$)$

em que: mf é a massa fresca; mt é a massa túrgida e ms é a massa seca.

A colheita foi realizada manualmente, quando os grãos estavam com aproximadamente $160 \mathrm{~g}$ de água $\mathrm{kg}^{-1}$ de grãos de milho e as espigas encontravam-se em R6. Para determinar o ponto de colheita levou-se em consideração a "linha do leite" e a formação da camada negra. As espigas foram debulhadas manualmente e os grãos tiveram sua umidade corrigida para $130 \mathrm{~g}$ de água $\mathrm{kg}$ de grãos de milho. $\mathrm{O}$ teor de água inicial dos grãos, foi determinado pelo método direto, em estufa com circulação forçada de ar a $60^{\circ} \mathrm{C}$, na temperatura de $105^{\circ} \mathrm{C}$ por 24 horas (BRASIL, 2009), após as correções determinou-se a massa de mil grãos e a produtividade em $\mathrm{kg} \mathrm{ha}^{-1}$.

Os dados obtidos foram submetidos à análise de variância ao nível de $5 \%$ de probabilidade pelo teste $\mathrm{F}$, com o auxílio do software SISVAR ${ }^{\circledR}$ (FERREIRA, 2011). Para as variáveis quantitativas, os modelos foram escolhidos baseando-se na significância dos coeficientes de regressão e utilizando o teste " $t$ " e adotando-se o nível de $5 \%$ de probabilidade de determinação assim como 0 valor de $\mathrm{R}^{2}$ (SQRegressão/SQtratamentos). Para fatores qualitativos adotou-se o teste de Tukey a 5\% de probabilidade.

\section{RESULTADOS}

Os dados meteorológicos, coletados junto a estação meteorológica da UFMT, durante todo o período do experimento estão apresentados nas figuras $1 \mathrm{a}, 1 \mathrm{~b}$ e $1 \mathrm{c}$. A temperatura e umidade relativa do ar foram os parâmetros meteorológicos que menos variaram (Figura 1 a e 1c). Por isso acredita-se que tiveram pouca interferência nos resultados do experimento. Os parâmetros meteorológicos que mais variaram durante o experimento foram a precipitação; radiação global e o período de insolação (Figura 1a e 1b).

Em relação à precipitação, esta atingiu altos valores entre os meses de fevereiro (395 $\mathrm{mm})$ e março $(180 \mathrm{~mm})$, reduzindo em abril $(62 \mathrm{~mm})$, maio $(28 \mathrm{~mm})$, junho $(16 \mathrm{~mm})$ e chegando a zero em julho (Figura 1a). Para a radiação global e o período de insolação, verificou-se que tanto a intensidade de radiação global, como o período de insolação foram maiores no início do período da safrinha, entre os dias 5 e 15 de fevereiro (Figura 1b), porém após este período houve redução nestas variáveis, durante boa parte dos meses de fevereiro e março, ocorrendo novo aumento nos valores médios destas variáveis nos meses de abril até junho, onde houve estabilização dos valores.

Os maiores valores de insolação e radiação global principalmente após o mês de fevereiro podem explicar os maiores valores de produtividade encontrados nas épocas de semeadura do final do mês de fevereiro/inicio de março.

O teor relativo de água (TRA) nas folhas de milho foi significativamente influenciado apenas pelas épocas de semeadura. A variável TRA teve comportamento quadrático decrescente, com o ponto de mínimo valor entre a semeadura dos dias $16 / 02$ e $23 / 02$, atingindo $74,34 \%$. O maior TRA foi verificado nas folhas das plantas da primeira semeadura (26/01) com de $91,49 \%$, TRA $23,1 \%$ superior ao ponto de mínimo encontrado (Figura 2).
Os menores valores de TRA encontrados durante o pendoamento das plantas, semeadas dia 23/02, ocorreu principalmente pela ausência de precipitação no período próximo a esta avaliação (28/04) (Figura 1a). A UR não influenciou este resultado, pois não ocorreram grandes alterações no período do dia $26 / 04$ a $06 / 05$, próximo ao pendoamento (Figura 1c).
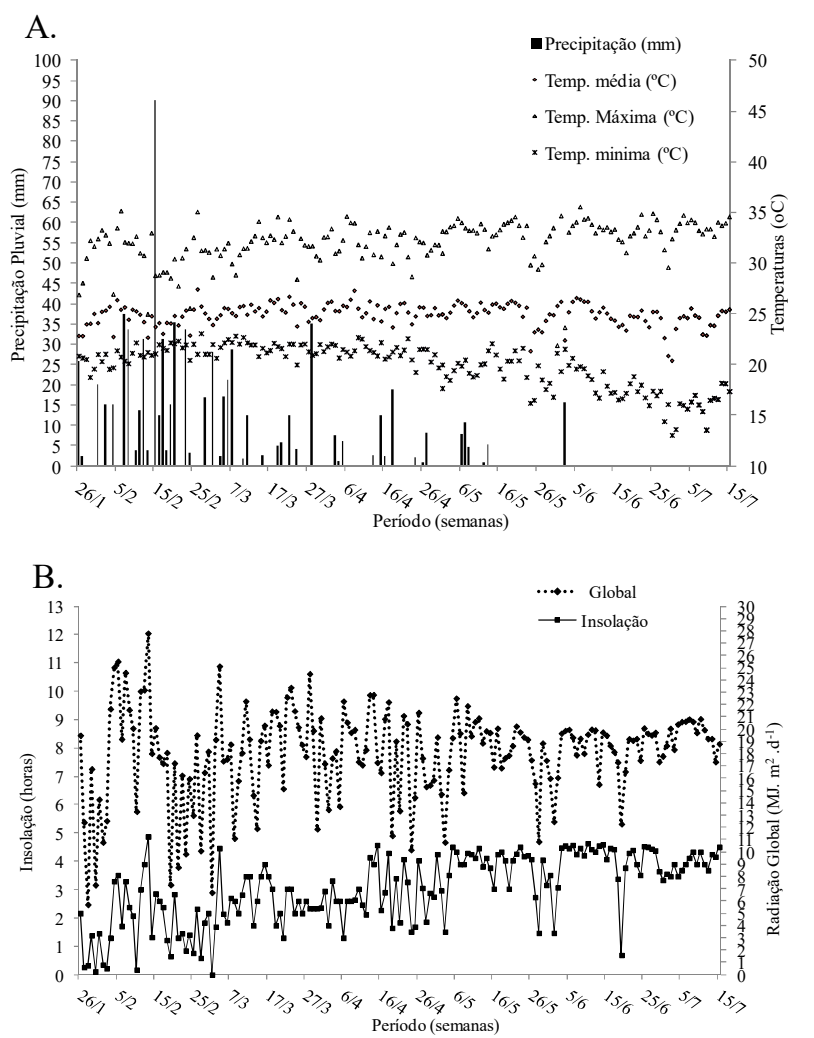

C.

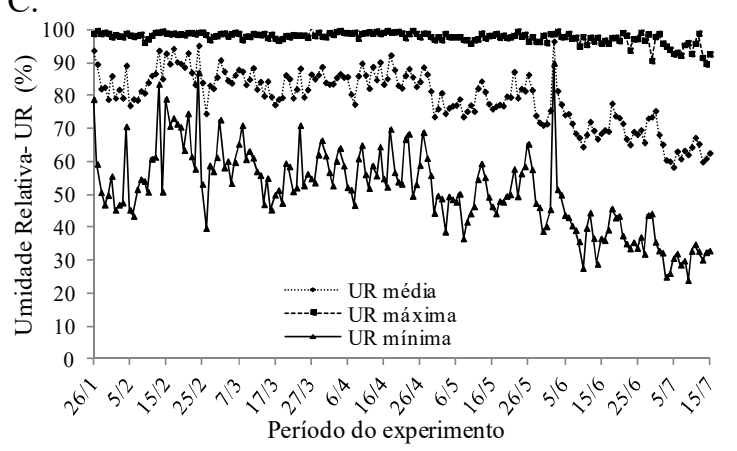

Figura 1. Dados de precipitação pluviométrica $(\mathrm{mm})$ e temperaturas do $\operatorname{ar}\left({ }^{\circ} \mathrm{C}\right)($ a) ; Tempo de insolação e radiação global (b) ; Umidades relativas do ar (\%) (c).

Figure 1. Average data of pluviometry precipitation $(\mathrm{mm})$ and temperatures air $\left({ }^{\circ} \mathrm{C}\right)(\mathrm{a})$; Time of insolation and global radiation (b); Umidades aerial relative do ar (\%) (c).

As variáveis: altura de planta e massa seca da parte aérea foram influenciadas, apenas pelas épocas de semeadura, não havendo diferença entre os híbridos ou a interação híbridos $\mathrm{x}$ épocas de semeadura.

A altura de planta e massa seca da parte aérea tiveram comportamento quadrático decrescente. A maior altura de planta ocorreu com a semeadura no dia 02/03 (Figura 3a), provavelmente devido as maiores intensidades luminosas que as plantas deste período de semeadura receberam, principalmente no início do ciclo (Figura 1c). A massa seca 
da parte aérea atingiu o ponto de mínimo valor também na semeadura do dia 16/02, com uma massa seca de aproximadamente 9 ton $\mathrm{ha}^{-1}$ (Figura $3 \mathrm{~b}$ ).

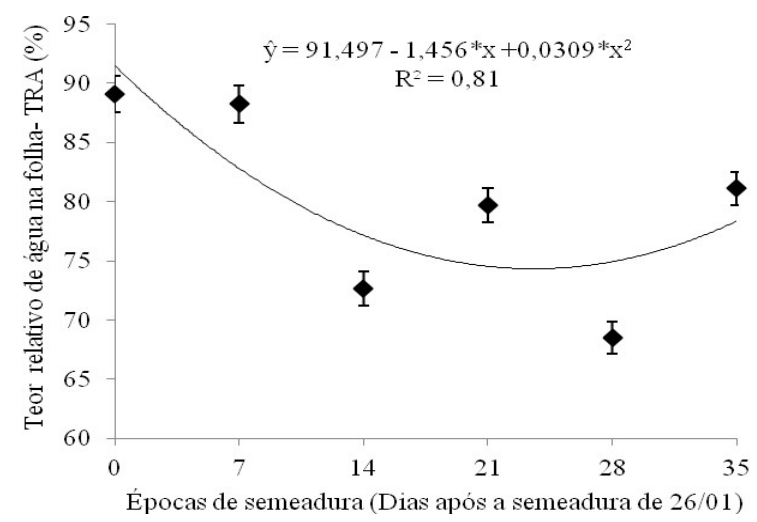

Figura 2. Teor relativo de água (\%), no estádio VT, de três híbridos de milho (Truck ${ }^{\circledR}(\operatorname{Syn} 7316)$, Status ${ }^{\circledR}\left(\right.$ Syn7205), Máximus $\left.{ }^{\circledR}\right)$, em seis épocas de semeadura na "segunda safra".

Figure 2. Relative water content (\%), in stage VT, for three híbrids Corn (Truck ${ }^{\circledR}(\operatorname{Syn} 7316)$, Status ${ }^{\circledR}\left(\right.$ Syn7205), Máximus $\left.{ }^{\circledR}\right)$, in six times sowing "off season". no início da "janela" de semeadura (26/01), com $6.373 \mathrm{~kg}$ ha 1 ou $106 \mathrm{sc} \mathrm{ha}^{-1}$ e no final do período da "janela" de semeadura na "segunda safra", entre os dias (15/02 a 03/03), atingindo com a semeadura no dia $23 / 02$ produtividade de aproximadamente $6.800 \mathrm{~kg} \mathrm{ha}^{-1}$ ou $113 \mathrm{sc} \mathrm{ha}^{-1}$.

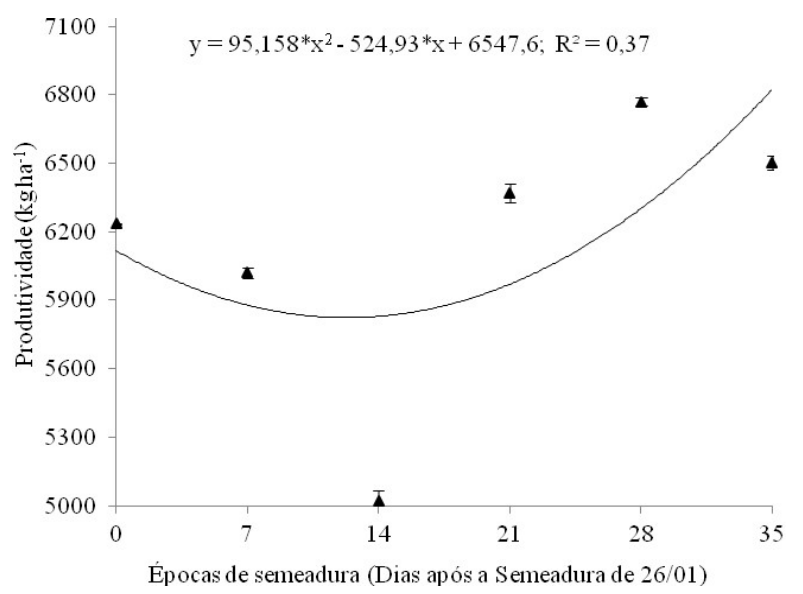

Figura 4. Produtividade de grãos $\left(\mathrm{Kg} \mathrm{ha}^{-1}\right)$ de três híbridos de milho (Truck ${ }^{\circledR}$ Syn7316, Status ${ }^{\circledR}$ syn7205, Máximus ${ }^{\circledR}$ ), em seis épocas de semeadura na "segunda safra".

Figure 4. a) Yield of grains $\left(\mathrm{Kg} \mathrm{ha}^{-1}\right)$, for three híbrids Corn (Truck ${ }^{\circledR}\left(\right.$ Syn7316), Status ${ }^{\circledR}\left(\right.$ Syn7205), Máximus $\left.{ }^{\circledR}\right)$, in six times sowing "off season".

\section{DISCUSSÃO}

Com relação aos valores de TRA nas folhas das plantas de milho, os maiores valores no inicio da "janela" de semeadura e ao final da "janela", são diretamente ligados à precipitação durante o ciclo de cultivo dos híbridos (Figura 1a). Silva et al. (2012), verificaram que o teor de água é afetado negativamente por períodos de estresse hídrico, o que diminui a pressão de turgescência nas células, devido à redução do fluxo da seiva pelos feixes vasculares, podendo ter impactos na produtividade.

Os maiores crescimentos vegetativos verificados no início e ao final da "janela" de semeadura estão relacionados com os maiores valores insolação e radiação global que as plantas destes períodos de semeadura receberam (Figura 1b). Sabe-se que o milho possui grande sensibilidade a aumentos da intensidade luminosa (LANDAU et al, 2009). Carmo et al. (2013), observaram, que as plantas submetidas a 50\% de luminosidade, aos 35 dias após a emergência, atingiram altura de $76,79 \mathrm{~cm}$, enquanto plantas submetidas a $100 \%$ de luminosidade, tiveram altura média de $117,68 \mathrm{~cm}$, uma diferença de 40,89 cm.

As plantas semeadas entre os dias 09/02 e 23/02, ou seja, no "meio" da "janela" de semeadura tiveram seu crescimento vegetativo menor e influenciado também pela luminosidade que as plantas foram expostas, pois; meses como janeiro a março, tem menor quantidade de insolação, apesar de possuírem maiores números de horas de insolação, astronomicamente (SILVA et al., 2012).

A produtividade não foi influenciada pela precipitação hídrica, uma vez que os híbridos atingiram as maiores produtividades $\left(6800 \mathrm{~kg} \mathrm{ha}^{-1}\right)$, mesmo semeados no final da "janela" de cultivo, com um volume hídrico menor do que das outras épocas de semeadura, com isso, acredita-se que o fator mais limitante tenha sido a radiação solar (luminosidade). Demétrio et al., (2008) verificaram que a 
redução da intensidade luminosa, especialmente ente V12 e $\mathrm{R} 1$, provoca redução na produtividade, neste período definese o tamanho de espigas e formação de estilo-estigma, ou seja número de grãos. Além disso, no inicio do período reprodutivo, chuvas esporádicas já são suficientes para a manutenção da produtividade, contribuindo nesta fase para o enchimento de grãos (CRUZ et al., 2010), fator este dos menos relevantes para a produtividade do milho (DEMÉTRIO et al, 2008).

Amaral Filho et al. (2005) verificaram redução no número de grãos por espiga com a redução de incidência luminosa próximo ao estádio VT, que consequentemente reduz a produção de fotoassimilados e a produtividade. Além da redução de fotoassimilados, níveis baixos de luminosidade reduzem a polinização reduzindo o número de grãos (DEMETRIO et al., 2008).

\section{CONCLUSÕES}

O milho tem maiores teores de água quando semeado no início da "janela" de semeadura dia 26/01 e 16/02; O milho semeado entre dias 16/02 e 23/02 na região de Sinop - MT apresentaram o menor teor de água nas folhas.

Durante a "janela" de semeadura, o menor crescimento vegetativo do milho em Sinop - MT ocorreu no período entre o dia $09 / 02$ e $23 / 02$.

Os híbridos Truck ${ }^{\circledR}$, Máximus ${ }^{\circledR}$ e Status ${ }^{\circledR}$ possuem produtividades semelhantes e expressando seu maior potencial produtivo quando semeados no final da "janela" de semeadura, entre os dias 16/02 a 02/03.

\section{REFERÊNCIAS}

AMARAL FILHO, J. P. R.; FORNASIERI FILHO, D.; FARINELLI, R.; BARBOSA, J. C. Espaçamento, densidade populacional e adubação nitrogenada na cultura do milho. Revista Brasileira de Ciência do Solo, Viçosa, MG, v. 29, n.3, p. 467-473, 2005. DOI: http://dx.doi.org/10.1590/S0100-06832005000300017

BRASIL. Ministério da Agricultura. Departamento Nacional de Produção Vegetal. Regras para análise de sementes. Brasília, 2009. 399p.

BORTOLINI, C. G. Sistemas produtivos de milho no estado do Mato Grosso. 2007. Artigo em Hipertexto. Disponível em: http://www.infobibos.com/Artigos/2007

1/MilhoMT/index.htm. Acesso em: 18/06/2015.

CARMO, M. S.; CRUZ, S. C. S.; SOUZA, E. J.; CAMPOS, L. F. C.; MACHADO, C. G. Doses e fontes de nitrogênio no desenvolvimento e produtividade de milho doce (Zea mays convar. saccharata var. rugosa). Bioscience Journal, Uberlândia, v. 28, n. 1, p. 223-231, 2012.

CONAB - Companhia Nacional de Abastecimento. Acompanhamento da safra brasileira: grãos, nono levantamento, junho de 2017. Disponível em

$<$ http://www.conab.gov.br/OlalaCMS/uploads/arquivos/17_0 6_08_09_02_48_boletim_graos_junho_2017.pdf.> Acesso $0 \overline{2} / 0 \overline{7} / 2107$

CRUZ, J. C.; SILVA, G. H. da; PEREIRA FILHO, I. A.; GONTIJO NETO, M. M.; MAGALHÃES, P. C. Caracterização do cultivo de milho safrinha de alta produtividade em 2008 e 2009. Revista Brasileira de Milho e Sorgo, Sete Lagoas, v. 9, n. 2, p. 177-188, 2010. DOI:http://dx.doi.org/10.18512/19806477/rbms.v9n2p17 7188
DEMÉTRIO, C. S.; FORNASIERI FILHO, D.; CAZETTA, J. O.; CAZETTA, D. A. Desempenho de híbridos de milho submetidos a diferentes espaçamentos e densidades populacionais. Pesquisa Agropecuária Brasileira, Brasília, v. 43, n. 12, p. 1691-1697, 2008. DOI: http://dx.doi.org/10.1590/S0100204X2008001200008

EMBRAPA - Empresa Brasileira de Pesquisa Agropecuária. Sistema brasileiro de classificação de solos. 2.ed. Rio de Janeiro: Embrapa Solos, 2006. 306p.

FERREIRA, D. F. Sisvar: A computer statistical analysis system. Ciência e Agrotecnologia, Lavras, v. 35, n. 6, p. 1039-1042, nov./dez. 2011. DOI: http://dx.doi.org/10.1590/S1413-70542011000600001

FORSTHOFER, E. L.; SILVA, P. R. F. da; STRIEDER, M. L.; MINETTO, T.; RAMBO, L.; ARGENTA, G.; SANGOI, L.; SUHRE, E.; SILVA, A. A. Desempenho agronômico e econômico do milho em diferentes sistemas de manejo e épocas de semeadura. Pesquisa Agropecuária Brasileira, Brasília, v. 41, n.3, p. 399407, 2006. DOI: http://dx.doi.org/10.1590/S0100204X2006000300005

GONÇALVES, S. L.; CARAMORI, P. H.; WREGEL, M. S.; SHIOGA, P.; GERAGE, A. C. É pocas de semeadura do milho "safrinha", no Estado do Paraná, com menores riscos climáticos. Acta Scientiarum Agronomy, Maringá, v. 24, n. 5, p. 1287-1290, 2002.

LANDAU, E. C.; SANS, L. M. A.; SANTANA, D. P. Clima e solo. In: CRUZ, J. C. (Ed.). Cultivo do milho. 5. ed. Sete Lagoas: Embrapa Milho e Sorgo, 2009. (Embrapa Milho e Sorgo. Sistemas de produção, 1). Acesso em: 10 jul. 2015.

SANGOI, L.; SCHMITT, A.; ZANIN, C. G. Área foliar e rendimento de grãos de híbridos de milho em diferentes populações de planta. Revista Brasileira de Milho e Sorgo, Sete Lagoas, v. 6, n.3, p. 263-271, 2007. DOI: http://dx.doi.org/10.18512/1980-6477/rbms.v6n03p\%25p SANS, L. M. A.; ASSAD, E. D.; GUIMARÃES, D. P.; AVELLAR, G. Zoneamento de riscos climáticos para a cultura de milho na Região Centro-Oeste do Brasil e para o Estado de Minas Gerais. Revista Brasileira de Agrometeorologia, Santa Maria, v. 9, n. 3, p. 527-535, 2001.

SILVA, C. E. S.; ROCHA, E. W. L.; MAGAlHÃES, P.; ALVES, V. C. Colloquium Agrariae, Maringá, v. 8, n. Especial, p. 37-41, 2012.

SOUZA, A. P.; MOTA, L. L.; ZAMADEI, T.; MARTIM, C. C.; ALMEIDA, F. T.; PAUlinO, J. Classificação climática e balanço hídrico climatológico no estado de Mato Grosso. Nativa, Sinop, v. 1, n.1, p. 34-43, 2013. DOI: http://dx.doi.org/10.14583/2318-7670.v01n01a07

PENARIOL, F. G.; FORNASIERI FILHO, D.; COICEV, L.; BORDIN, L.; FARINELLI, R. Comportamento de cultivares de milho semeadas em diferentes espaçamentos entre linhas e densidades populacionais, na safrinha. Revista Brasileira de Milho e Sorgo, Sete Lagoas, v. 2, n. $2, \quad$ p. 52-60, 2003. DOI: http://dx.doi.org/10.18512/1980-6477/rbms.v2n02p\%25p

PEREIRA, C. S.; MAIA, L. F. P.; PAULA, F. S. de. Aplicação de extrato etanólico de própolis no crescimento e produtividade do feijoeiro comum. Revista Ceres, Viçosa, v. 61, n. 1, p. 98-104, 2014. DOI: http://dx.doi.org/10.1590/S0034-737X2014000100013 